\title{
Núcleo de Prática Jurídica: necessidade, implementação e diferencial qualitativo
}

\author{
Center of Legal Practice:necessity, implementation \\ and qualitative diferential
}

\author{
Vladmir Oliveira da Silveira* \\ Samyra Naspolini Sanches*
}

\section{Resumo}

A presente pesquisa tem por objeto o Núcleo de Prática Jurídica (NPJ) e visa responder sobre a necessidade dele na formação do bacharel em Direito, como pode se dar sua implementação e quais os diferenciais qualitativos de sua execução. Trata-se de um estudo descritivo e exploratório, realizado com base na pesquisa bibliográfica e histórica, servindo-se do método indutivo.

Palavras-chave: Ensino jurídico. Educação jurídica. Núcleo de Prática Jurídica. Diretrizes curriculares. Curso de Direito.

\section{Abstract}

The present research has as its object the Center of Legal Practice (NPJ) and aims to answer the need of it in the formation of Bachelor of Law, how may occur your implementation and what are the execution differential qualitatives. Because this was a descriptive, exploratory study will be conducted based on bibliographical and history research, using the inductive method.

Keywords: Legal teaching. Legal Education. Center for legal practice. Curriculum guidelines. Law school.

Doutor em Direito pela PUC/SP, professor e diretor do Centro de Pesquisa em Direito da Universidade Nove de Julho (UNINOVE), professor da PUC/SP, presidente do Conselho Nacional de Pesquisa em Direito (CONPEDI). São Paulo - SP - Brasil. E-mail: vladmir@aus.com.br

* Doutora em Direito pela PUC/SP, professora e pesquisadora do Centro de Pesquisa em Direito da Universidade Nove de Julho (UNINOVE), professora do Mestrado em Direito de Araçatuba (SP). São Paulo - SP - Brasil. E-mail: samyra@mrsconsult.com.br 


\section{Introdução}

O ensino jurídico no Brasil, recentemente denominado pela Ordem dos Advogados do Brasil (OAB) de educação jurídica, apresenta sérios problemas desde seus primórdios, e as críticas que recebe vão desde a metodologia ao próprio conhecimento disseminado em sala de aula.

É certo que tal problemática se insere no quadro geral da educação superior em nosso país, mas não é esse assunto o escopo do presente trabalho, merecendo estudo específico para uma abordagem adequada.

Segundo Rodrigues (2000, p. 16), "a realidade do ensino jurídico no Brasil é que ele não forma, deforma" (grifo do autor). Apesar de o Direito encontrar-se entre os cursos mais procurados no vestibular e de formar todos os anos um número de bacharéis superior ao que o mercado de trabalho pode absorver, existe uma reclamação generalizada por bons profissionais. Isso se explica em grande parte pela má qualidade do ensino jurídico. "É necessário reformulá-lo. Essa é uma constatação geral". (RODRIGUES, 2000, p. 16). Em estudo específico sobre o assunto, Unger (2001, p. 1-29) conclui enfaticamente:

O problema do ensino de Direito no Brasil é um caso extremo. Como está não presta. Não presta, nem para ensinar os estudantes a exercer o Direito, em qualquer de suas vertentes profissionais, nem para formar pessoas que possam melhorar o nível da discussão dos nossos problemas, das nossas instituições e das políticas públicas. Representa um desperdício, maciço e duradouro, de muitos dos nossos melhores talentos. $E$ frustra os que, como alunos ou professores, participam nele: quanto mais sérios, mais frustrados.

No contexto da educação jurídica, a presente pesquisa terá por objeto o Núcleo de Prática Jurídica (NPJ), objetivando responder sobre a necessidade de sua existência na formação do bacharel em Direito, sobre como ocorre sua implementação e quais os diferenciais qualitativos de sua execução. Por tratar-se de estudo descritivo e exploratório, será realizado com base na pesquisa bibliográfica e histórica, utilizando-se do método indutivo. 


\section{Considerações históricas sobre o ensino jurídico no Brasil}

Segundo Pôrto (2000), o início da grande reforma do ensino jurídico no Brasil foi desencadeado pela Comissão de Ciência e Ensino Jurídico, criada em agosto de 1991 pelo Conselho Federal da OAB, por iniciativa de seu presidente à época, Marcello Lavenère Machado. Encarregada de diagnosticar a situação do ensino jurídico e apresentar propostas de solução, a Comissão era composta pelos professores Paulo Luiz Neto Lôbo (coordenador), Roberto Armando Ramos de Aguiar (relator), Álvaro Villaça Azevedo, Edmundo Lima de Arruda Júnior, José Geraldo de Sousa Júnior e Sérgio Ferraz.

A Comissão decidiu iniciar seus trabalhos a partir do "diálogo criativo com os autores, pensadores, professores e pesquisadores que nos últimos anos vêm refletindo e formulando propostas significativas acerca dos problemas do ensino jurídico" (OAB, 1992, p. 7), sendo a consulta realizada em forma de questionário dirigido àqueles que desenvolveram vasta produção acadêmica preocupada com as questões atinentes ao ensino jurídico. Todos os caminhos apontavam para o diagnóstico de uma "crise" (RODRIGUES, 1993).

As respostas constituíram um completo raio-X da situação e foram publicadas em 1992, na primeira de uma série de obras da Comissão sobre o tema, com o título de OAB Ensino Jurídico: diagnósticos, perspectivas e propostas.

O mapeamento revelou que se tratava de uma "crise" maior do que a imaginada.

Em primeiro lugar, percebeu-se que, tradicionalmente, no Brasil, o currículo mínimo termina por converter-se no máximo e é, em geral, composto de matérias codificadas - ou seja, dogmáticas.

O ensino do Direito com base em manuais que reproduzem o paradigma dogmático da ciência jurídica se transforma em uma educação conservadora e tradicional, a qual, a partir do estudo abstrato das normas jurídicas, desconhece as reais necessidades sociais, 
restringindo-se à análise da validade de tais normas e olvidando por completo as questões de sua eficácia e legitimidade.

Observou-se que era mantida, outrossim, a tradição dos cursos jurídicos pátrios, de total alienação e despolitização (FARIA, 1987), em que, para estudar a lei, são deixadas de lado questões de suma importância para o país, tais como: corrupção, impunidade, direitos humanos e meio ambiente, para citar alguns exemplos.

A formação para a cidadania, que o estudo do Direito necessariamente deveria abordar, bem como o combate às formas de opressão e exclusão na sociedade brasileira exigem "uma cultura jurídica capaz de ir ao encontro da realidade social, de imaginá-la e construí-la como direito" (UNGER, 2001, p. 1-29). Mas isso, como se pôde constatar, não era estimulado de nenhuma maneira nas faculdades.

No que diz respeito às questões didático-pedagógicas, o ensino jurídico realizava-se basicamente com a mesma metodologia da época de sua criação - a aula-conferência. Também conhecida como "aula coimbrã", numa alusão ao método praticado na Universidade de Coimbra, em Portugal, a aula-conferência caracteriza-se por ser expositiva e ministrada a um elevado número de alunos em uma mesma sala de aula.

O conteúdo da aula normalmente se resumia a comentários de Códigos por meio do método dedutivo (RODRIGUES, 1993). As faculdades de Direito foram consideradas "como redutos de uma transmissão arcaica do saber jurídico, empreendida, quase sempre, por profissionais bem-sucedidos e indiferentes às modernas exigências pedagógicas e metodológicas" (WARAT; CUNHA, 1977, p. 53).

A relação do professor com o aluno era de estilo tradicional, sendo este considerado um recipiente vazio de conteúdo a ser preenchido pelo saber oriundo do professor - que é, por sua vez, o detentor do conhecimento a ser transmitido pela educação formal. Tal transmissão autoritária do conhecimento gera como resposta a memorização passiva dos alunos, que pode até servir para a obtenção de um título universitário, mas não os habilita a decisões maduras e autônomas. 
Com o tempo, o conhecimento assimilado mecanicamente será esquecido e, dessa forma, o aluno não adquire as habilidades necessárias para desenvolver o raciocínio jurídico ou elaborar novos conhecimentos, uma vez que foi "treinado" somente para ler e decorar, e não para ler, refletir e escrever.

Quanto ao corpo docente, em sua maioria, os professores não possuíam nenhum conhecimento de metodologias didáticas ou teorias pedagógicas. Também não buscavam aperfeiçoar seu saber teórico e interdisciplinar acerca do fenômeno jurídico; possuíam apenas a graduação e não se interessavam por cursos de pós-graduação ou de aperfeiçoamento. Eram escolhidos entre profissionais competentes e de renome em suas cidades e exerciam a atividade docente como um "bico" a proporcionar-lhes status social e favorecê-los em suas profissões fora da faculdade. Por isso, muitos professores não viviam a realidade acadêmica nem se dedicavam à pesquisa, limitando-se a ensinar o Direito da forma como aprenderam - vale dizer, mediante leitura e comentários aos artigos dos Códigos, adotando um ou mais livrostextos cujo conteúdo será o único cobrado dos alunos nas padronizadas avaliações (RODRIGUES, 1993).

Assim, o ensino recebido em sala de aula era o responsável isolado pela formação do aluno, não havendo qualquer atividade extraclasse que concorresse para sua formação.

O perfil do aluno-padrão sempre foi o do acomodado. Dentre os vários motivos que o levam a escolher o Direito como curso superior, encontram-se, não raro, a falta de opção ou o fato de essa atividade profissional ser exercida por algum membro da família. Em sua maioria, os alunos não frequentam bibliotecas e não desenvolvem trabalhos de pesquisa e/ou extensão. O objetivo é passar pela faculdade da maneira mais tranquila possível e, ao final, obter o diploma que, acreditam eles, abrirá as portas do mercado de trabalho em um "passe de mágica", como ocorria no início dos cursos jurídicos.

O mesmo acontecia com o Estágio de Prática Jurídica, o qual, apesar de fundamental para a formação do bacharel - não só como 
advogado, mas nas outras carreiras jurídicas -, resumia-se a uma atividade de fachada, relegada ao cumprimento de um serviço assistencialista e restrito a somente algumas atividades, como o Direito de Família ${ }^{1}$. Assim, a pouca formação prática que havia, quando havia, restringia-se à advocacia contenciosa, como se o curso servisse somente para formar advogados. Esse era o "estado da crise" do ensino jurídico no Brasil.

A Comissão, então, elaborou um questionário destinado ao Levantamento das Condições dos Cursos Jurídicos no País, distribuído em todas as faculdades de Direito no segundo semestre de 1992, com o objetivo de conhecer uma realidade até então desconhecida. "Uma realidade obscurecida, mantida sob relações de poder e hierarquia, cuja função social nunca foi discutida publicamente" (PÔRTO, 2000, p. 64). Com tal pesquisa, foi dado o primeiro passo no processo de avaliação dos cursos de Direito brasileiros. Os resultados e as reflexões da Comissão foram reunidos no segundo livro da referida série, denominado $O A B$ Ensino Jurídico: parâmetros para a elevação de qualidade e avaliação.

De posse dos resultados da pesquisa inédita, a Comissão da $\mathrm{OAB}$, em parceria com o MEC, realizou, durante o ano de 1993, quatro seminários com todos os interessados na transformação do ensino jurídico. Os seminários, ocorridos em Porto Alegre, Recife, São Paulo e Brasília, contaram com a participação da comunidade jurídica acadêmica e profissional (PÔRTO, 2000).

Como proposta, fruto de tal processo de reflexão, pesquisa, avaliação e discussão nos seminários, foi editada, em dezembro de 1994, a Portaria MEC n 1.886/94, que fixava as novas diretrizes curriculares e o conteúdo mínimo para os cursos jurídicos de todo o Brasil, com obrigatoriedade a partir de 1996.

Buscando melhorar a qualidade dos cursos jurídicos, a referida Portaria previu uma gama de mudanças:

Vide Anexo 1. 
a) exigiu duração mínima de 5 anos para os cursos jurídicos (antes eram 4);

b) tornou obrigatórias as atividades de pesquisa e extensão, denominadas atividades complementares, com no mínimo $5 \%$ e no máximo $10 \%$ da carga horária da grade curricular; ${ }^{2}$

c) fixou as disciplinas consideradas obrigatórias, divididas entre as fundamentais (com exigência de Filosofia Jurídica, Ética etc.) e as profissionalizantes, deixando à escolha dos cursos as disciplinas complementares a serem inseridas na grade, conforme as peculiaridades regionais ${ }^{3}$;

d) dispôs sobre o acervo bibliográfico de cada curso, com no mínimo 10 mil volumes, além de periódicos de jurisprudência, doutrina e legislação ${ }^{4}$; e

e) prescreveu a obrigatoriedade da defesa de monografia de final de curso perante banca examinadora, com tema e orientador escolhidos pelo próprio aluno ${ }^{5}$.

O até então chamado Estágio de Prática Forense ou Estágio Supervisionado recebeu especial atenção por parte da Portaria. Inovando em relação a todas as previsões normativas anteriores, tornouse obrigatório o mínimo de 300 horas de atividades, sem restringir-se à área advocatícia, mas incluindo várias carreiras jurídicas. O curso deveria criar um Núcleo de Prática Jurídica para o desenvolvimento de tais atividades, incluindo as práticas reais tratadas no escritóriomodelo, mas também as simuladas, em que o aluno vivenciaria o papel da magistratura e do Ministério Público, bem como a mediação e a arbitragem ${ }^{6}$.

\footnotetext{
Artigos $3^{\circ}$ e $4^{\circ}$ da Portaria $n^{\circ} 1.886 / 94$, em anexo.

Artigo $6^{\circ}$ da Portaria $n^{\circ} 1.886 / 94$, em anexo.

Artigo $5^{\circ}$ da Portaria $n^{\circ} 1.886 / 94$, em anexo.

Artigo $9^{\circ}$ da Portaria $n^{\circ} 1.886 / 94$, em anexo.

Artigos de 10 a 13 da Portaria $n^{\circ} 1.886 / 94$, em anexo.
} 
A Portaria $n^{\circ} 1.886 / 94$ fixava um prazo de dois anos, a contar da data de sua publicação, para os cursos jurídicos cumprirem as determinações. O prazo não foi respeitado e, em 1996, o próprio MEC, pela Portaria $n^{\circ} 03 / 96$, postergou a obrigatoriedade para o ano seguinte, 1997. Já em 2001, pelas Portarias MEC n 1.252/01 e n 1.875/01, a monografia de final de curso foi tornada obrigatória apenas para alunos que tivessem iniciado o curso de Direito em 1998.

Em 1996, a Lei de Diretrizes e Bases da Educação Nacional (LDB) determinou que cada curso de graduação deveria elaborar suas diretrizes curriculares. Três anos depois, em 1999, no âmbito do MEC/ SESu, foi designada uma Comissão - composta pelos professores Paulo Luiz Neto Lôbo, Roberto Fragale Filho, Sérgio Luiz Souza Araújo e Loussia Musse Felix - para elaborar as novas diretrizes.

Por entender que as diretrizes curriculares contidas na Portaria $n^{\circ} 1.886 / 94$ eram as que melhor se enquadravam no que seria necessário a um curso jurídico - e até mesmo em respeito ao processo que culminou na própria Portaria -, a Comissão manteve-as na nova proposta, realizando algumas modificações, fruto do amadurecimento e da experiência de implantação.

Em abril de 2002, a Câmara de Educação Superior, pelo Parecer $n^{\circ} 146 / 02$, definiu as diretrizes curriculares de um conjunto de cursos superiores, dentre os quais o de Direito. Toda definição sobre a duração do curso, a carga horária e o tempo de integralização curricular, bem como do estágio e das atividades complementares, era remetida aos mínimos constantes do Parecer n 100, de 13 de março de 2002, que não especificava, todavia, a carga horária mínima para o estágio curricular.

A publicação da homologação do Parecer n 146/2002 gerou uma série de protestos de várias associações profissionais, dentre elas, a $\mathrm{OAB}$ e a Associação dos Magistrados Brasileiros, além de entidades de representação acadêmica, como a Associação Brasileira de Ensino do Direito (ABEDi), a Federação Nacional dos Estudantes de Direito (FENED) e o Colégio Brasileiro de Faculdades de Direito. Tais protestos, baseados na perda da qualidade do ensino de Direito, fizeram com que o 
então Ministro da Educação reabrisse a discussão acerca das diretrizes, paralisando o processo de validação do Parecer na CES.

Após várias discussões com as entidades interessadas, o MEC publicou a Resolução $n^{\circ}$ 09/2004, mantendo a obrigatoriedade do Núcleo de Prática Jurídica nos moldes da Portaria nº 1.886/94.

\section{Necessidade do Núcleo de Prática Jurídica}

Ainda que a ciência jurídica seja considerada técnica, com a finalidade específica de promover a aplicação da lei ao caso concreto mediante a subsunção, o ensino do Direito, desde a implantação das primeiras faculdades, em 1827, sempre privilegiou a transmissão de conhecimento em sala de aula.

Sob tal viés, Birnfeld (2003) separa a história do estágio curricular nos cursos jurídicos em três momentos: a) o que ele denomina "préhistória", que vai de 1827, com a criação das faculdades de Direito, até 1972; b) de 1972 até a Portaria MEC n 1.886/94; e c) da Portaria $n^{\circ}$ 1.886 até os dias atuais.

O que se observa no período "pré-histórico" é que nem sempre houve uma atividade "prática" obrigatória. E quando houve, foi sem previsão de carga horária mínima e ocorrendo, via de regra, em sala de aula.

As chamadas aulas práticas nada mais eram do que aulasconferência, em que os professores passavam aos alunos modelos de petições, autos findos para análise e exercícios programados.

É importante lembrar que a necessidade de um estágio prático foi imposta pelo Estatuto da OAB de 1963, em especial para os bacharéis que quisessem se inscrever nos quadros da Ordem.

Por imperativo do Estatuto, a reforma de 1972 exigiu a implantação dos chamados escritórios-modelo nas faculdades, onde os alunos poderiam desenvolver questões práticas referentes à vida real. 
A vida real, todavia, era restrita a poucos casos de assistência judiciária gratuita, os quais, por uma série de exclusões de competência, acabavam se resumindo ao Direito de Família.

De qualquer forma, a obrigatoriedade do estágio derivava da OAB e, mesmo com sua previsão na forma de estágio supervisionado, por meio da reforma de 1972, não se estipulara uma carga horária mínima para seu cumprimento. Por outro lado, as atividades em sala de aula ainda predominavam nesse período.

Dentre os problemas do ensino jurídico diagnosticados pela avaliação, o Estágio de Prática Jurídica configurava um dos mais graves, já que o bacharel saía da faculdade sem a menor noção do que era a prática profissional, despreparado para o mercado de trabalho e desconhecedor das realidades locais e regionais.

Lembra Rodrigues (2002, p. 29) que o Estágio Supervisionado é "um conjunto de atividades práticas, reais ou simuladas, voltadas ao campo de trabalho, no qual o profissional vai exercer suas atividades depois de formado". Para tanto, não poderia jamais ser confundido ou ministrado como aula expositiva.

Por tais razões, a Portaria $n^{\circ} 1.886 / 94$ foi além da questão do estágio curricular e exigiu que este fosse acompanhado de outras atividades importantes para a formação prática do bacharel, tendo lugar o que se denominou Núcleo de Prática Jurídica (NPJ). Este nasceu com a Resolução n 09/2004, que, ao subdividir a formação do bacharel em Eixo de Formação Fundamental, Eixo de Formação Profissional e Eixo de Formação Prática, destacou neste último o Núcleo de Prática Jurídica. Eis o que dispõe o artigo $7^{\circ}$ da Resolução ${ }^{7}$ :

Art. $7^{\circ} \mathrm{O}$ Estágio Supervisionado é componente curricular obrigatório, indispensável à consolidação dos desempenhos profissionais desejados, inerentes ao perfil do formando, devendo cada instituição, por seus colegiados próprios,

BRASIL. Ministério da Educação. Secretaria de Ensino Superior. Resolução nº 09/2004. 
aprovar o correspondente regulamento, com suas diferentes modalidades de operacionalização.

$\S 1^{\circ} \mathrm{O}$ Estágio de que trata este artigo será realizado na própria instituição, através do Núcleo de Prática Jurídica, que deverá estar estruturado e operacionalizado de acordo com regulamentação própria, aprovada pelo conselho competente, podendo, em parte, contemplar convênios com outras entidades ou instituições e escritórios de advocacia; em serviços de assistência judiciária implantados na instituição, nos órgãos do Poder Judiciário, do Ministério Público e da Defensoria Pública ou ainda em departamentos jurídicos oficiais, importando, em qualquer caso, na supervisão das atividades e na elaboração de relatórios que deverão ser encaminhados à Coordenação de Estágio das IES, para a avaliação pertinente.

$\S 2^{\circ}$ As atividades de Estágio poderão ser reprogramadas e reorientadas de acordo com os resultados teórico-práticos gradualmente revelados pelo aluno, na forma definida na regulamentação do Núcleo de Prática Jurídica, até que se possa considerá-lo concluído, resguardando, como padrão de qualidade, os domínios indispensáveis ao exercício das diversas carreiras contempladas pela formação jurídica. (grifo nosso) cadê?

Conclui-se que a presença do Núcleo de Prática Jurídica nos cursos de Direito é uma necessidade indiscutível. Por isso, em seguida, abordaremos como ocorre sua implementação.

\section{Implementação do Núcleo de Prática Jurídica}

Inicialmente, cumpre destacar a diferença entre estágio supervisionado, escritório-modelo e Núcleo de Prática Jurídica, pois, em muitas instituições de ensino superior (IES), os três se sobrepõem.

O NPJ é um local, dentro da IES, onde se realizam as atividades do eixo de formação prática, previsto na Resolução nº 09/2004. 
No escritório-modelo, são desenvolvidas as atividades práticas reais que a lei considera como de assistência judiciária gratuita e, em algumas instituições, também as atividades simuladas atinentes à advocacia. A principal crítica feita ao estágio restrito ao escritóriomodelo era que a formação prática não era completa, uma vez que se direcionava somente à formação do advogado.

Já o estágio supervisionado é a atividade curricular obrigatória que contempla as ações do escritório-modelo e uma série de outras, todas desenvolvidas pelo e no Núcleo de Prática Jurídica.

O Núcleo de Prática Jurídica é, pois, mais amplo que o escritóriomodelo, o qual, por sua vez, é o locus de desenvolvimento das atividades do estágio supervisionado.

A Resolução n 09/2004 prevê a existência do NPJ sem, contudo, detalhar sua estrutura. Assim, as instituições têm se utilizado dos parâmetros apostos pela Portaria $n^{\circ} 1.886 / 94$, a qual prevê que ele disporá de instalações adequadas para treinamento das atividades profissionais de advocacia, magistratura, Ministério Público e demais profissões jurídicas, incluindo o atendimento ao público ${ }^{8}$.

As atividades desenvolvidas devem ser exclusivamente práticas, abarcando redação de peças processuais e profissionais, rotinas processuais, assistência e atuação em audiências e sessões, visitas a órgãos judiciários, prestação de serviços jurídicos e técnicas de negociação coletiva, arbitragens e conciliação, tudo sob controle, orientação e avaliação do Núcleo de Prática Jurídica ${ }^{9}$.

Sugere, ainda, que tais atividades podem ser complementadas por convênios entre Defensoria Pública ou outras entidades públicas ou privadas, ou até mesmo em juizados especiais, a se instalarem nas dependências da própria IES. 
Cumpridas as exigências mínimas para o funcionamento do NPJ, vejamos como elas podem ser executadas de maneira qualificada.

\section{Diferencial qualitativo do Núcleo de Prática Jurídica}

Cumpridas as exigências mínimas para o funcionamento do NPJ e observando sua implantação em todo país, surgem questões para reflexão, a fim de aumentar a qualidade dos Núcleos e destacar seus diferenciais, a depender da vocação e do perfil do egresso de cada curso.

Como o NPJ não é uma atividade estanque em relação ao restante do curso jurídico, são aplicados a ele o perfil do egresso e os objetivos do curso, escolhidos no respectivo projeto pedagógico. Dessa forma, não se pode conceber que nos mais de mil cursos jurídicos de todo o Brasil sejam os NPJs todos iguais.

Destarte, é de suma importância observar as características regionais dos NPJs. Algumas áreas do Direito possuem aplicação semelhante em todo o Brasil, como o Direito Civil e o Penal, mas demandas locais fazem com que a prática de outras áreas tenha relevância não só pedagógica, mas social e econômica. Densidade populacional, problemas urbanos e migratórios, atividade empresarial, proteção do meio ambiente, relação com o consumidor e atividade alfandegária são situações que determinam o perfil social e a vocação econômica de certas regiões - o que torna importante a prática do regime jurídico atinente a essas matérias. Pode não ter sentido, por exemplo, a prática de Direito Ambiental em São Paulo, assim como seria dispensável a prática em mercado financeiro na capital de Roraima, Boa Vista.

Outra questão importante para o diferencial qualitativo do NPJ são os docentes. Costuma-se criticar a docência de um advogado na área de Teoria Geral do Direito, sob o argumento de que ele não tem tempo para pesquisa. Entretanto, não faria sentido, num NPJ, empregar um professor de dedicação exclusiva (40 horas) que dificilmente sabe o que 
acontece no balcão - ou seja, não tem a prática forense. O percentual de docentes profissionais nos cursos jurídicos deveria ser alocado em sua grande parte no NPJ, pois são docentes que realmente possuem experiência da prática profissional para compartilhar com seus alunos.

Ao mesmo tempo, não se pode contratar um profissional "clínico geral" para um NPJ, pois é desejável que o docente tenha pleno domínio na militância da área que Ihe foi atribuída para lecionar.

Deve-se atentar, de igual modo, para que as ações de práticas simuladas sejam elaboradas por professores e advogados experientes, além de renovadas a cada semestre, evitando que venham a se converter em atividades pró-forma, caracterizadas pela repetição de casos e peças processuais - o que leva muitos alunos a copiar as peças de colegas do semestre anterior. É o que se pode chamar "pacto da preguiça" ou "pacto da mediocridade", em que professores e alunos, os dois lados da relação de aprendizagem, convencionam reproduzir o conteúdo, desperdiçando o momento em que a pesquisa se aplica à prática. $\mathrm{Na}$ verdade, o conteúdo deveria ser renovado e melhorado o tempo todo. Só assim - mediante uma atividade estimulante e pedagógica - o NPJ ganharia efetividade; caso contrário restará como único aprendizado o "método Lavoisier" (nada se cria, tudo se transforma ou se copia).

Caso similar acontece nas disciplinas dogmáticas, nas quais a metodologia de ensino consiste na repetição e leitura de manuais, gerando total desestímulo na frequência às aulas e pesquisa acadêmica. No momento da avaliação, basta ao aluno, depois de decorar o conteúdo dos manuais, repeti-lo na prova. Aliás, Streck (1999) afirma que, em nosso país, estabeleceu-se uma "cultura jurídica standard", na qual os manuais jurídicos oferecem ao jurista, na prática de sua profissão, "soluções e conceitos lexicográficos", uma coletânea de "prêt-à-porter significativos" que comporão o conteúdo de suas petições, pareceres e sentenças, "com ementas jurisprudenciais que são citadas, no mais das vezes, de forma descontextualizada".

Por outro lado, os casos simulados acarretam um problema de maior extensão. Se no NPJ o aluno copia o modelo, na segunda fase do 
Exame da Ordem, não saberá elaborar nova peça. Em outro momento, enquanto advogado, copiará a peça do colega. Já na pós-graduação, o então aluno e advogado sem criatividade tenderá ao plágio.

Importa também salientar que, por tratar-se da parte do curso jurídico em que o aluno toma contato com a população, realizando verdadeira atividade de extensão, tal oportunidade deve ser aproveitada para realizar uma prestação de serviço que ultrapasse os parâmetros da mera assistência judiciária gratuita, para converter-se em uma experiência mais ampla e enriquecedora tanto para ele quanto para o curso e a própria sociedade.

Ressalte-se que nenhuma atividade do Núcleo de Prática Jurídica deve ser paga, pois a população-alvo é carente. Ou seja, o NPJ é o local onde o aluno convive com uma realidade social diferente da sua e terá contato com aspectos dessa realidade que jamais imaginou - 0 que confere ao Núcleo a importante função de sensibilizá-lo para as desigualdades sociais com que se depara cotidianamente o profissional do Direito.

Como enfatiza Pereira (2011, p. 6), "a finalidade social desses espaços pode avançar no esclarecimento da população sobre os direitos, fortalecendo o processo de participação popular para melhoria do funcionamento do aparato administrativo estatal". Com isso, potencializa-se o exercício da cidadania na comunidade em que se insere o NPJ.

O acesso à Justiça também deve ser função do NPJ, "assegurando o atendimento e assistência judiciária, além de promover ações de caráter educativo, destinadas a informar, esclarecer e peticionar demandas" (PEREIRA, 2011, p. 7).

\section{Conclusão}

O presente artigo buscou investigar a necessidade do Núcleo de Prática Jurídica para a formação do bacharel em Direito, como deve se 
dar sua implementação e quais os desafios a enfrentar para a qualidade e excelência das atividades ali desenvolvidas.

Iniciou-se com uma contextualização histórica da educação jurídica em nosso país, destacando o papel dos estágios curriculares nas diversas grades e matrizes que regularam a matéria desde a criação das primeiras faculdades de Direito no Brasil.

No contexto da educação jurídica, constatou-se que o Núcleo de Prática Jurídica tem apresentado vários problemas e desafios a serem superados.

O primeiro é constituir-se enquanto prática jurídica real, desvencilhando-se da tradição de aulas expositivas, caracterizadas principalmente por modelos de petição.

Outro desafio é superar a limitação da atividade do NPJ como mera assistência judiciária restrita à prática advocatícia na área específica do Direito de Família.

Verificou-se, outrossim, que a atuação do NPJ é muito mais ampla do que a realizada no escritório-modelo e deve ser o locus primordial de atividades práticas reais e simuladas que preparem o bacharel para enfrentar o mercado de trabalho, consciente das especificidades regionais e comprometido tanto com o acesso à Justiça quanto com o enfrentamento dos problemas sociais de nosso país.

\section{Referências}

ADEODATO, J. M. Ética e retórica: para uma teoria da dogmática jurídica. São Paulo: Saraiva, 2002.

AGUIAR, R. A. R. de. A crise da advocacia no Brasil: diagnóstico e perspectivas. São Paulo: Alfa-Omega, 1991.

BIRNFELD, C. A. Estágio de prática jurídica: uma realidade em construção. In: ANUÁRIO ABEDI. Florianópolis: Boiteux, 2003. p. 6379. 
CARLINI, A.; CERQUEIRA, D. T.; ALMEIDA FILHO, J. C. de A. (Org.). 180 anos do ensino jurídico no Brasil. Campinas, SP: Millenium, 2008.

FARIA, J. E. A reforma do ensino jurídico. Porto Alegre: SAFE, 1987.

LÔBO, P. L. N. Critérios de avaliação externa dos cursos jurídicos. Revista da OAB, Brasília, DF, n. 57, p. 21-25, maio/mar. 1994.

LYRA FILHO, R. O direito que se ensina errado. Brasília, DF: UnB, 1980.

NASPOLINI SANCHES, S.; MAILLART, A. S. Críticas ao ensino jurídico brasileiro: aspectos epistemológicos, funcionais e operacionais. In: CONGRESSO NACIONAL DO CONPEDI., 20., 2011, Belo Horizonte. Anais... Belo Horizonte, 2011. p. 3963-3984.

ORDEM DOS ADVOGADOS DO BRASIL. Conselho Federal. 170 anos de cursos jurídicos no Brasil. Brasília, DF, 1997.

. Ensino jurídico: balanço de uma experiência. Brasília, DF, 2000.

. Ensino jurídico: diagnóstico, perspectivas e propostas. Brasília, DF, 1992.

. Ensino jurídico: novas diretrizes curriculares. Brasília, DF, 1996.

. Ensino jurídico: parâmetros para elevação de qualidade e avaliação. Brasília, DF, 1993.

OAB recomenda: um retrato dos cursos jurídicos. Brasília, DF, 2001.

O ENSINO jurídico no Brasil. Revista da OAB, Brasília, DF, v. XIV, n. 29, p. 94-110, set./dez. 1981.

PEREIRA, N. C. F. O núcleo de prática jurídica no currículo do curso de direito para o fortalecimento do acesso ao judiciário na formação do bacharel em Direito. In: CONGRESSO NACIONAL DO CONPEDI, 20, 2011, Belo Horizonte. Anais... Belo Horizonte, 2011. p. 8764-8783. 
PÔRTO, I. da F. Ensino jurídico, diálogos com a imaginação: construção do projeto didático no ensino jurídico. Porto Alegre: SAFE, 2000.

RODRIGUES, H. W. Ensino jurídico e direito alternativo. São Paulo: Acadêmica, 1993.

. Ensino jurídico e realidade social. Seqüência, Florianópolis, n. 17, p. 77-87, dez. 1988.

RTr, 1995.

. Novo currículo mínimo dos cursos jurídicos. São Paulo: . (Org.). Ensino jurídico para que(m). Florianópolis: Boiteux, 2000.

RODRIGUES, H. W.; JUNQUEIRA, Eliane Botelho. Ensino do direito no Brasil: diretrizes curriculares e avaliação das condições de ensino. Florianópolis: Boiteux, 2002.

STRECK, L. L. Hermenêutica jurídica e(m) crise: uma exploração hermenêutica da construção do direito. Porto Alegre: Max Limonad, 1999.

UNGER, R. M. Uma nova faculdade de direito no Brasil. São Paulo: EDESP/FGV, 2001.

VILLELA, J. B. Ensino do direito: equívocos e deformações. Educação, Brasília, DF, v. 3, n. 12, p. 40-48, abr./jun. 1974.

WARAT, L. A.; CUNHA, R. M. C. da. Ensino e saber jurídico. Rio de Janeiro: Eldorado, 1977.

WARAT, L. A. et al. O poder do discurso docente das escolas de direito. Seqüência, Florianópolis, v. 1, n. 2, p. 146-152, 1980.

Recebido em: 28/11/12

Aprovado em: 07/01/13 


\section{ANEXO 01}

Tabela sobre a previsão do estágio nas diretrizes curriculares dos Cursos Jurídicos

\begin{tabular}{|c|c|}
\hline Ano & Previsão legal de Estágio \\
\hline 1827 & $\begin{array}{l}\text { Estágio Supervisionado: Prática do Processo } \\
\text { adotado pelas leis do Império (junto com a } \\
\text { disciplina de Teoria). }\end{array}$ \\
\hline 1891 e 1895 & Estágio Supervisionado: Prática Forense. \\
\hline 1931 & $\begin{array}{l}\text { Estágio Supervisionado: } \\
\text { - Direito Judiciário Civil (Prática) } \\
\text { - Direito Judiciário Penal (Prática) }\end{array}$ \\
\hline 1962 & $\begin{array}{l}\text { Estágio Supervisionado: Prática Forense como } \\
\text { conteúdo de Direito Judiciário. }\end{array}$ \\
\hline Resolução n 03/1972 & $\begin{array}{l}\text { Estágio Supervisionado: Prática Forense (sem } \\
\text { carga horária definida). } \\
\text { Sem obrigatoriedade. }\end{array}$ \\
\hline Portaria no 1.886/1994 & $\begin{array}{l}\text { Prática Jurídica obrigatória com no mínimo } 300 \\
\text { horas-aula no Núcleo de Prática Jurídica. }\end{array}$ \\
\hline Parecer $n^{\circ} 146 / 2002$ & $\begin{array}{l}\text { Prática Jurídica obrigatória com no máximo } \\
15 \% \text { da carga horária total do curso. } \\
\left.\text { (Parecer } n^{\circ} 100 / 2002\right) \text {. } \\
\text { Sem obrigatoriedade do Núcleo de Prática } \\
\text { Jurídica. }\end{array}$ \\
\hline Resolução nº 09/2004 & $\begin{array}{l}\text { Prática Jurídica obrigatória com no máximo } \\
15 \% \text { da carga horária total do curso (Parecer } \\
100 / 2002) \text {. } \\
\text { Com obrigatoriedade do Núcleo de Prática } \\
\text { Jurídica. }\end{array}$ \\
\hline
\end{tabular}




\section{ANEXO 02}

\section{PORTARIA № 1.886, DE 30 DE DEZEMBRO DE 1994 \\ Fixa as diretrizes curriculares e o conteúdo mínimo do curso jurídico}

O Ministro da Educação e do Desporto, no uso das atribuições do Conselho Nacional de Educação, na forma do artigo $4^{\circ}$ da Medida Provisória $n^{\circ} 765$, de 16 de dezembro de 1994, e considerando o que foi recomendado nos Seminários Regionais e Nacional de Cursos Jurídicos, e pela Comissão de Especialistas de Ensino de Direito, da SESU-MEC, resolve:

Art. $1^{\circ} \mathrm{O}$ curso jurídico será ministrado no mínimo de 3.300 horas de atividades, cuja integralização se fará em pelo menos cinco e no máximo oito anos letivos.

Art. $2^{\circ} \mathrm{O}$ curso noturno, que observará o mesmo padrão de desempenho e qualidade do curso no período diurno, terá um máximo diário de quatro horas de atividades didáticas.

Art. $3^{\circ} \mathrm{O}$ curso jurídico desenvolverá atividades de ensino, pesquisa e extensão, interligadas e obrigatórias, segundo programação e distribuição aprovadas pela própria Instituição de Ensino Superior, de forma a atender às necessidades de formação fundamental, sóciopolítica, técnico-jurídica e prática do bacharel em direito.

Art. $4^{\circ}$ Independentemente do regime acadêmico que adotar o curso (seriado, créditos ou outro), serão destinados cinco a dez por cento de carga horária total para atividades complementares ajustadas entre o aluno e a direção ou coordenação do curso, incluindo pesquisa, extensão, seminários, simpósios, congressos, conferências, monitoria, iniciação científica e disciplinas não previstas no currículo pleno .

Art $5^{\circ}$ Cada curso jurídico manterá um acervo bibliográfico atualizado de no mínimo dez mil volumes de obras jurídicas e de referência as 
matérias do curso, além de periódicos de jurisprudência, doutrina e legislação.

Art. $6^{\circ} \mathrm{O}$ conteúdo mínimo do curso jurídico, além do estágio, compreenderá as seguintes matérias, que podem estar contidas em uma ou mais disciplinas do currículo pleno de cada curso.

I - Fundamentais: Introdução ao Direito, Filosofia (geral e jurídica), Ética (geral e profissional), Sociologia (geral e jurídica), Economia e Ciência Política (com Teoria do Estado),

II - Profissionalizantes: Direito Constitucional, Direito Civil, Direito Administrativo, Direito Tributário. Direito Penal, Direito Processual Civil, Direito Processual Penal. Direito do Trabalho, Direito Comercial e Direito Internacional.

Parágrafo único. As demais matérias e novos direitos serão incluídos nas disciplinas em que se desdobrar o currículo pleno de cada curso, de acordo com suas peculiaridades e com observância de interdisciplinaridade.

Art. $7^{\circ}$ A prática de educação física, com predominância desportiva, observará a legislação específica.

Art. $8^{\circ} \mathrm{A}$ partir do $4^{\circ}$ ano, ou do período letivo correspondente, e observado o conteúdo mínimo previsto no art. $6^{\circ}$, poderá o curso concentrar-se em uma ou mais áreas de especialização, segundo suas vocações e demandas sociais e de mercado de trabalho.

Art. $9^{\circ}$ Para conclusão do curso, será obrigatória apresentação e defesa de monografia final, perante banca examinadora, com tema e orientador escolhidos pelo aluno.

Art. 10. O estágio de prática jurídica, supervisionado pela instituição de ensino superior, será obrigatório e integrante do currículo pleno, em um total mínimo de 300 horas de atividades práticas simuladas e reais desenvolvidas pelo aluno sob controle e orientação do núcleo correspondente.

$\S 1^{\circ}$ o núcleo de prática jurídica, coordenado por professores do curso, 
disporá de instalações adequadas para treinamento das atividades profissionais de advocacia, magistratura, Ministério Público, demais profissões jurídicas e para atendimento ao público.

$\S 2^{\circ}$ As atividades de prática jurídica poderão ser complementadas mediante convênios com a Defensoria Pública outras entidades públicas judiciárias empresariais, comunitárias e sindicais que possibilitem a participação dos alunos na prestação de serviços jurídicos e em assistência jurídica, ou em juizados especiais que venham a ser instalados em dependência da própria instituição de ensino superior

Art. 11. As atividades do estágio supervisionado serão exclusivamente práticas, incluindo redação de peças processuais e profissionais, rotinas processuais, assistência e atuação em audiências e sessões, visitas a órgãos judiciários, prestação de serviços jurídicos e técnicas de negociações coletivas, arbitragens e conciliação, sob o controle, orientação e avaliação do núcleo de prática jurídica.

Art. 12. O estágio profissional de advocacia, previsto na Lei 8.906, de 04/07/1994, de caráter extracurricular, inclusive para graduados, poderá ser oferecido pela Instituição de Ensino Superior, em convênio com a $\mathrm{OAB}$, complementando-se a carga horária efetivamente cumprida no estágio supervisionado, com atividades práticas típicas de advogado e de estudo do Estatuto da Advocacia e da OAB e do Código de Ética e Disciplina.

Parágrafo único. A complementação da carga horária, no total estabelecido no convênio, será efetivada mediante atividades no próprio núcleo de prática jurídica, na Defensoria Pública, em escritórios de advocacia ou em setores jurídicos, públicos ou privados, credenciados e acompanhados pelo núcleo e pela OAB.

Art. 13. O tempo do estágio realizado em Defensoria Pública da União, do Distrito Federal ou dos Estados, na forma do artigo 145, da Lei Complementar $n^{\circ} 80$, de 12 de janeiro de 1994, será considerado para fins de carga horária do estágio curricular previsto no artigo 10 desta Portaria. 
Art. 14. As instituições poderão estabelecer convênios de intercâmbio dos alunos e docentes, com aproveitamento das respectivas atividades de ensino, pesquisa, extensão e prática jurídica.

Art. 15. Dentro do prazo de dois anos, a contar desta data, os cursos jurídicos proverão os meios necessários ao integral cumprimento desta Portaria.

Art. 16. As diretrizes curriculares desta Portaria são obrigatórias aos novos alunos matriculados a partir de 1996 nos cursos jurídicos que, no exercício de sua autonomia, poderão aplicá-las imediatamente.

Art. 16 As diretrizes curriculares desta Portaria são obrigatórias aos novos alunos matriculados a partir de 1997 nos cursos jurídicos que, no exercício de sua autonomia, poderão aplicá-las imediatamente. (Nova Redação dada pela Portaria Ministerial nº 003, de 09 de janeiro de 1996) Art. 17. Esta Portaria entrará em vigor na data de sua publicação, revogadas as disposições em contrário, especialmente as Resoluções 03/72 e 15/73 do extinto Conselho Federal de Educação.

MURÍLIO DE AVELLAR HINGEL 


\section{ANEXO 03}

\section{Resolução CNE/CES 9/2004}

Resolução CNE/CES 9/2004. Diário Oficial da União, Brasília, $1^{\circ}$, de outubro de 2004, Seção 1, pgs. 17 e 18.

CONSELHO NACIONAL DE EDUCAÇÃO

CÂMARA DE EDUCAÇÃO SUPERIOR

RESOLUÇÃO CNE/CES N 9, DE 29 DE SETEMBRO DE 2004

Institui as Diretrizes Curriculares Nacionais do Curso de Graduação em Direito e dá outras providências.

O Presidente da Câmara de Educação Superior do Conselho Nacional de Educação, no uso de suas atribuições legais, com fundamento no art. $9^{\circ}$, § $2^{\circ}$, alínea "c", da Lei $n^{\circ} 4.024$, de 20 de dezembro de 1961, com a redação dada pela Lei ${ }^{\circ} 9.131$, de 25 de novembro de 1995, tendo em vista as diretrizes e os princípios fixados pelos Pareceres CES/CNE n ${ }^{\circ}$ S 776/97, 583/2001, e 100/2002, e as Diretrizes Curriculares Nacionais elaboradas pela Comissão de Especialistas de Ensino de Direito, propostas ao CNE pela SESu/MEC, considerando o que consta do Parecer CES/CNE 55/2004 de 18/2/2004, reconsiderado pelo Parecer CNE/CES 211, aprovado em 8/7/2004, homologado pelo Senhor Ministro de Estado da Educação em 23 de setembro de 2004,

Resolve:

Art. $1^{\circ}$. A presente Resolução institui as Diretrizes Curriculares do Curso de Graduação em Direito, Bacharelado, a serem observadas pelas Instituições de Educação Superior em sua organização curricular.

Art. $2^{\circ}$. A organização do Curso de Graduação em Direito, observadas as Diretrizes Curriculares Nacionais, se expressa através do seu projeto pedagógico, abrangendo o perfil do formando, as competências e habilidades, os conteúdos curriculares, o estágio curricular 
supervisionado, as atividades complementares, o sistema de avaliação, o trabalho de curso como componente curricular obrigatório do curso, o regime acadêmico de oferta, a duração do curso, sem prejuízo de outros aspectos que tornem consistente o referido projeto pedagógico.

$\S 1^{\circ}$ O Projeto Pedagógico do curso, além da clara concepção do curso de Direito, com suas peculiaridades, seu currículo pleno e sua operacionalização, abrangerá, sem prejuízo de outros, os seguintes elementos estruturais:

I - concepção e objetivos gerais do curso, contextualizados em relação às suas inserções institucional, política, geográfica e social;

II - condições objetivas de oferta e a vocação do curso;

III - cargas horárias das atividades didáticas e da integralização do curso;

IV - formas de realização da interdisciplinaridade;

V - modos de integração entre teoria e prática;

VI - formas de avaliação do ensino e da aprendizagem;

VII - modos da integração entre graduação e pós-graduação, quando houver;

VIII - incentivo à pesquisa e à extensão, como necessário prolongamento da atividade de ensino e como instrumento para a iniciação científica;

IX - concepção e composição das atividades de estágio curricular supervisionado, suas diferentes formas e condições de realização, bem como a forma de implantação e a estrutura do Núcleo de Prática Jurídica;

X -concepção e composição das atividades complementares; e

$\mathrm{XI}$ - inclusão obrigatória do Trabalho de Curso.

$\S 2^{\circ}$ Com base no princípio de educação continuada, as IES poderão incluir no Projeto Pedagógico do curso, oferta de cursos de pósgraduação lato sensu, nas respectivas modalidades, de acordo com as efetivas demandas do desempenho profissional. 
Art. $3^{\circ}$. O curso de graduação em Direito deverá assegurar, no perfil do graduando, sólida formação geral, humanística e axiológica, capacidade de análise, domínio de conceitos e da terminologia jurídica, adequada argumentação, interpretação e valorização dos fenômenos jurídicos e sociais, aliada a uma postura reflexiva e de visão crítica que fomente a capacidade e a aptidão para a aprendizagem autônoma e dinâmica, indispensável ao exercício da Ciência do Direito, da prestação da justiça e do desenvolvimento da cidadania.

Art. $4^{\circ}$. O curso de graduação em Direito deverá possibilitar a formação profissional que revele, pelo menos, as seguintes habilidades e competências:

I - leitura, compreensão e elaboração de textos, atos e documentos jurídicos ou normativos, com a devida utilização das normas técnicojurídicas;

II - interpretação e aplicação do Direito;

III - pesquisa e utilização da legislação, da jurisprudência, da doutrina e de outras fontes do Direito;

IV - adequada atuação técnico-jurídica, em diferentes instâncias, administrativas ou judiciais, com a devida utilização de processos, atos e procedimentos;

V - correta utilização da terminologia jurídica ou da Ciência do Direito;

VI - utilização de raciocínio jurídico, de argumentação, de persuasão e de reflexão crítica;

VII - julgamento e tomada de decisões; e

VIII - domínio de tecnologias e métodos para permanente compreensão e aplicação do Direito.

Art. $5^{\circ}$. O curso de graduação em Direito deverá contemplar, em seu Projeto Pedagógico e em sua Organização Curricular, conteúdos e atividades que atendam aos seguintes eixos interligados de formação:

I - Eixo de Formação Fundamental, tem por objetivo integrar o estudante 
no campo, estabelecendo as relações do Direito com outras áreas do saber, abrangendo dentre outros, estudos que envolvam conteúdos essenciais sobre Antropologia, Ciência Política, Economia, Ética, Filosofia, História, Psicologia e Sociologia.

II - Eixo de Formação Profissional, abrangendo, além do enfoque dogmático, o conhecimento e a aplicação, observadas as peculiaridades dos diversos ramos do Direito, de qualquer natureza, estudados sistematicamente e contextualizados segundo a evolução da Ciência do Direito e sua aplicação às mudanças sociais, econômicas, políticas e culturais do Brasil e suas relações internacionais, incluindo-se necessariamente, dentre outros condizentes com o projeto pedagógico, conteúdos essenciais sobre Direito Constitucional, Direito Administrativo, Direito Tributário, Direito Penal, Direito Civil, Direito Empresarial, Direito do Trabalho, Direito Internacional e Direito Processual; e

III - Eixo de Formação Prática, objetiva a integração entre a prática e os conteúdos teóricos desenvolvidos nos demais Eixos, especialmente nas atividades relacionadas com o Estágio Curricular Supervisionado, Trabalho de Curso e Atividades Complementares.

Art. $6^{\circ}$. A organização curricular do curso de graduação em Direito estabelecerá expressamente as condições para a sua efetiva conclusão e integralização curricular de acordo com o regime acadêmico que as Instituições de Educação Superior adotarem: regime seriado anual; regime seriado semestral; sistema de créditos com matrícula por disciplina ou por módulos acadêmicos, com a adoção de pré-requisitos, atendido o disposto nesta Resolução.

Art. $7^{\circ}$. O Estágio Supervisionado é componente curricular obrigatório, indispensável à consolidação dos desempenhos profissionais desejados, inerentes ao perfil do formando, devendo cada instituição, por seus colegiados próprios, aprovar o correspondente regulamento, com suas diferentes modalidades de operacionalização.

$\S 1^{\circ} \mathrm{O}$ Estágio de que trata este artigo será realizado na própria instituição, através do Núcleo de Prática Jurídica, que deverá estar estruturado e 
operacionalizado de acordo com regulamentação própria, aprovada pelo conselho competente, podendo, em parte, contemplar convênios com outras entidades ou instituições e escritórios de advocacia; em serviços de assistência judiciária implantados na instituição, nos órgãos do Poder Judiciário, do Ministério Público e da Defensoria Pública ou ainda em departamentos jurídicos oficiais, importando, em qualquer caso, na supervisão das atividades e na elaboração de relatórios que deverão ser encaminhados à Coordenação de Estágio das IES, para a avaliação pertinente.

$\S 2^{\circ}$ As atividades de Estágio poderão ser reprogramadas e reorientadas de acordo com os resultados teórico-práticos gradualmente revelados pelo aluno, na forma definida na regulamentação do Núcleo de Prática Jurídica, até que se possa considerá-lo concluído, resguardando, como padrão de qualidade, os domínios indispensáveis ao exercício das diversas carreiras contempladas pela formação jurídica.

Art. $8^{\circ}$. As atividades complementares são componentes curriculares enriquecedores e complementadores do perfil do formando, possibilitam o reconhecimento, por avaliação de habilidades, conhecimento e competência do aluno, inclusive adquirida fora do ambiente acadêmico, incluindo a prática de estudos e atividades independentes, transversais, opcionais, de interdisciplinaridade, especialmente nas relações com o mercado do trabalho e com as ações de extensão junto à comunidade.

Parágrafo único. A realização de atividades complementares não se confunde com a do Estágio Supervisionado ou com a do Trabalho de Curso.

Art. 9०. As Instituições de Educação Superior deverão adotar formas específicas e alternativas de avaliação, interna e externa, sistemáticas, envolvendo todos quantos se contenham no processo do curso, centradas em aspectos considerados fundamentais para a identificação do perfil do formando.

Parágrafo único. Os planos de ensino, a serem fornecidos aos alunos antes do início de cada período letivo, deverão conter, além dos 
conteúdos e das atividades, a metodologia do processo de ensinoaprendizagem, os critérios de avaliação a que serão submetidos e a bibliografia básica.

Art. 10. O Trabalho de Curso é componente curricular obrigatório, desenvolvido individualmente, com conteúdo a ser fixado pelas Instituições de Educação Superior em função de seus Projetos Pedagógicos.

Parágrafo único. As IES deverão emitir regulamentação própria aprovada por Conselho competente, contendo necessariamente, critérios, procedimentos e mecanismos de avaliação, além das diretrizes técnicas relacionadas com a sua elaboração.

Art. 11. A duração e carga horária dos cursos de graduação serão estabelecidas em Resolução da Câmara de Educação Superior.

Art. 12. As Diretrizes Curriculares Nacionais desta Resolução deverão ser implantadas pelas Instituições de Educação Superior, obrigatoriamente, no prazo máximo de dois anos, aos alunos ingressantes, a partir da publicação desta.

Parágrafo único. As IES poderão optar pela aplicação das DCN aos demais alunos no período ou ano subseqüente à publicação desta.

Art. 13. Esta Resolução entrará em vigor na data de sua publicação, ficando revogada a Portaria Ministerial $n^{\circ} 1.886$, de 30 de dezembro de 1994 e demais disposições em contrário.

\section{Edson de Oliveira Nunes}

Presidente da Câmara de Educação Superior 